\title{
LA MATERNIDAD COMO ARQUETIPO DE LA ÉTICA DEL CUIDADO. REFLEXIÓN CRÍTICA SOBRE LAS IDENTIDADES DE GÉNERO EN LA COMUNICACIÓN
}

\author{
MOTHERHOOD AS ARCHETYPE OF CARING ETHICS. CRTITICAL REFLEXION \\ ON THE GENDER IDENTITIES IN COMMUNICATION
}

Juan Carlos Suárez Villegas

Universidad de Sevilla

\section{RESUMEN:}

En este artículo se analiza las funciones vitales asociadas a la maternidad y se reivindica como imaginario ético que debe ser compartido por los hombres como posibilidades vitales de su desarrollo personal. A partir de aquí se propone una reconstrucción del discurso igualitaria con una perspectiva más fecunda de modelo de responsabilidades compartidas. Para lograr este objetivo se insiste en la importancia de los medios de comunicación como educadores permanentes de la opinión pública.

\section{Palabras claves:}

Maternidad, ética, cuidado, hombre, masculinidad, comunicación.

\section{Abstract:}

This paper analyze the vital functions associated with motherhood and claimed as ethical horizon for men personal development. Because of this we propose a review of gender discourses on equality and propose female points of views as much more creative for human virtues flourishing, based on mutual dependences and responsibilities. Mass media are permanent educators of citizen and one of their important function is illustrate a correct meaning of gender equality.

\section{KEY WORD:}

Motherhood, ethics, caring, men, masculinity, communication. 


\section{LA MATERNIDAD COMO CONCEPTO ARQUETÍPICO DE LA ÉTICA}

La visión ética asociada la maternidad reivindica la prioridad de la vida en su sentido más igualitario, el de las relaciones de mutua interdependencia en las que las acciones hacia el otro no se realizan con el afán de afirmar una posición de superioridad, sino en su sentido más auténtico del "poder", como capacidad de administrar al otro un bien del que participan ambos. Por eso, quien tiene "poder" desarrolla una capacidad de escuchar a los otros vitalmente. Decimos vitalmente para diferenciarlo de la estética del "oído", entendida como el gesto formal de un diálogo de sordos que se utiliza para confirmar lo que se haya previamente decidido. El poder en femenino es una democracia de la vida, una educación para hacer al otro la vida más fácil, más libre, más responsable. Sabiendo que sus decisiones tienen un precio y que ese precio no es el de los números, sino el del propio sentido vital.

Los éxitos externos, aquellos que permiten obtener la felicitación de todos, pero en los que el sujeto se advierte a sí mismo esclavo de objetivos que fueron desplazando hasta el infinito sus propios deseos, constituyen esas formas de antipoder, del poder deshumanizado que obliga a los individuos a prescindir de su ámbito vital para llegar a ser lo que otros esperan de él. Hay que reivindicar que lo femenino es positivo netamente. Son ventajas vitales, sobre las cuales cabe construir otro concepto de poder, otras voces distintas sobre el desarrollo humano. Lo femenino ha desarrollado una mayor empatía por la vida. Quizás porque poseen el gesto más generoso de la condición humana, ser portadora de la vida y darla. Desde luego no es ese el fin de las mujeres, craso error convertir tan extraordinaria virtud en un límite de la libertad personal. Todo lo contrario, la maternidad precisamente es un signo de la creatividad femenina, de su capacidad para construir relaciones humanas, las cuales constituyen también una garantía para la interpretación del mundo en otros ámbitos de la actividad humana.

Lo femenino es positivo y los hombres no debemos privarnos de esa parte de nuestra naturaleza. Lo hemos aprendido de nuestras madres, lo hemos comprobado en nuestras compañeras: se trata de profundizar en la densidad de las relaciones humanas, de un acercamiento a los otros en su situación vital, sin prisa, sin objetivos, sin reglas ni normas que nos impidan entender realidades desnudas, que se construyen a la par que se explican.

Este diseño de las relaciones de los primeros peldaños de la vida será sobre el que se sustente la construcción bipolar de nuestra cultura sobre lo masculino y lo femenino. Esta dicotomía debe ser desenmascarada. No existe un espacio de lo femenino y otro de lo masculino como virtudes asociadas a los sexos. Se trata de una convención cultural que convierte la sexualidad en categorías estancas dando lugar a dos géneros que dividen lo humano por la mitad. De este error somos víctimas todos, unos porque representando posiciones híbridas entre ambos extremos serán vistos como representaciones distorsionadas con respecto a la convención, otros, porque absurdamente asumiendo dichas categorías tendrán un concepto de nosotros mismos que pueden llegar a experimentar como si fuera impuesto. Queda así delimitado un sentido de la identidad que tendrá un carácter normativo sobre nuestras elecciones. La moralidad se disfraza así de "sexualidad" y en función de ella se les exige a las personas distintos deberes y se les marca distintas expectativas.

Esa es la igualdad discriminatoria, la que ha propiciado que muchas mujeres crean que la única manera de tomarse en serio sus aspiraciones profesionales sea asumiendo los valores y roles de los hombres: la competitividad, la disponibilidad absoluta al trabajo y la renuncia a cualquier otra responsabilidad que esté por encima de este. El resultado ha sido el trágico vaciamiento de la vida privada, de ese espacio de valores humanos vinculados a los afectos y a la comunicación con los otros. La primera referencia para medir la igualdad entre hombres y mujeres consiste en romper las estructuras de valores sociales asociados al género. Se conseguiría así también romper una jerarquía axiológica sobre las funciones correspondientes a unos y a otros y facilitaría un intercambio dentro de un proyecto común. La igualdad se respeta cuando hemos sido educados en igualdad, pues en quien sigue creyendo que su identidad constituye ya una diferencia "moral" con respecto a los demás, existe una discriminación latente que se manifestará no sólo en lo que hace sino también en lo que no hace. Las creencias y actitudes constituyen el clima que propician los posteriores comportamientos hacia los demás.

Este diseño de poder está tan instalado en nuestro modo de ver la vida, que prácticamente consideramos que las actividades que no reportan algún tipo de beneficio económico son actividades "privadas". Existen servicios públicos básicos que prestamos como personas y que se consideran privados. Así, por ejemplo, si uno coge un taxi se estima un servicio público porque media una relación dineraria, si lo hace un padre o una madre es una relación privada. La atención que se presta a un paciente en un hospital es un servicio público, la que prestan los familiares en casa es una relación privada. Lo público y lo privado se marca por relaciones de "poder" basado en el coste de la actividad. Lo voluntario es gratis, luego no tiene valor. Por este motivo, todo lo que se hace en el ámbito privado se estima un acto de servicio, una especie de deber de quien lo asume con respecto a su familia. Su actividad por intensa que sea no adquiere el estatus de profesional. Son "sus labores" o, en términos más cínicos, directamente se le convierte en "ama de casa". Ya por lo menos, manda en algo, aunque sea en eso privado de valor. La dinámica de las relaciones de dominación 
se expresa en el ejercicio de nominar y entender el significado de cada situación desde la mirada de quien ostenta el poder.

\section{EdUCACIÓn EN VALORES DE CUIDADO Y MASCULINIDAD}

El ser humano es constitutivamente masculino y femenino, como dos conjuntos de valores disponibles para su realización vital. De manera cultural y de acuerdo con los estadios socioevolutivos ha existido una cierta asignación de roles entre lo masculino y lo femenino, como si estuvieran ligados a los cuerpos. Sin embargo, aunque biológicamente existen diferencias obvias entre hombres y mujeres, siendo la posibilidad de la maternidad una experiencia exclusivamente de las mujeres, no hemos de considerar que la maternidad como experiencia humana corresponde exclusivamente a ella. La maternidad consiste en un conjunto de valores que se realizan a través de las vivencias con los seres que forman parte de un proyecto familiar. En este sentido, hay que reivindicar una maternidad masculina o, mejor dicho, la maternidad se complementa en el ejercicio de esta por parte del padre y no exclusivamente de la madre. Esta distinción entre la maternidad biológica y la maternidad vital se aprecia, por ejemplo, en el hecho de que pueden existir madres biológicas que tras haber pasado por la experiencia no quieren ejercer de madre en su vida. La prueba de este tipo de falta de maternidad se expresa en el "des-cuidado" de quienes forman parte de la experiencia. Pero esta dejación de la maternidad también puede encontrarse en la figura del padre, quien limita su función a su aportación biológica y se mantiene como un huésped de la existencia de sus propios hijos. Ambos casos son expresiones de una falta de maternidad vital.

Desde el punto de vista biológico la maternidad consiste en alojar la formación de una nueva criatura en el propio cuerpo y convertirlo en su morada existencial hasta su nacimiento. Se produce así un alumbramiento de una persona que ha formado parte de la propia vida de la madre de un modo íntimo. Dicha experiencia también puede ser atribuida al padre, aunque su grado de participación es necesariamente menor, pues la experiencia del cuerpo es insustituible y será la mujer quien sienta a su hijo y con su hijo. Una vez producido el nacimiento del hijo comienza la maternidad vital, la cual requiere la participación de ambos congéneres. La mujer atraviesa en el período inicial un proceso quizás más intenso de empatía con un hijo que ha sido formado en su cuerpo. Esta raíz biológica tendrá siempre una fuerza simbólica especial que evocará tanto en la madre como en la criatura una unión misteriosa con el sentido de sus vidas. Sin embargo, el padre contempla la posibilidad de desarrollar una maternidad intensa con su hijo en un proceso que guarda similitud con aquel otro biológico. Desde el punto de vista vital, la criatura es alojada en un entorno afectivo, moral y social que requiere de la participación de todos los miembros que componen la esfera familiar.
La función del padre y de la madre en esta experiencia es insustituible, pues a ambos les corresponde ejercer la maternidad vital: el alojamiento de la vida de los hijos en un espacio simbólico de valores vitales que deberían ser compartidos. Por eso, un modo metafórico de denominar a la responsabilidad masculina sería la de reivindicar su lado de "maternidad", entendida como una actitud existencial de cuidado y complicidad en la comunicación con los hijos. Pues la mujer es madre pero no exclusivamente madre, como el hombre es padre pero no exclusivamente padre y, a su vez, ser padre y madre son dos formas convencionales de calificar a experiencias asociadas a los sexos, las cuales han de permanecer abiertas a ambos como catálogos de funciones de dependencia hacia los demás como personas que somos.

Ahora bien, no se trata de una mera inversión de roles, como si se tuviera que asumir una función que no es propia. Esta manera de participar no aporta los elementos ontológicos a la experiencia de la maternidad masculina, pues no es hacer de madre sino ser maternal, entendido como un ejercicio que comporta un modo de estar en la relación con los hijos. La maternidad incluye, por tanto, un cambio a nivel psicológico y social sobre la posición que ha de ocupar el hombre en el ámbito familiar, siendo esta una experiencia de la que culturalmente se ha visto excluido. Por eso, cuando un hombre muestra actitudes o comportamientos maternales se le feminiza, como si ellos no correspondieran a su condición masculina. Existe una muralla simbólica en la que los hombres actúan en su función maternal con cierto recelo, como si tuvieran que pasar por ella de puntilla y evitar confusiones socialmente incómodas. En cierto sentido, la sociedad patriarcal se ha tendido una trampa acerca de su identidad, la cual a fuerza de enfatizar un modelo de valores considerados superiores propicia en el hombre complejo de inferioridad cuando opta por desarrollar otras cualidades de su identidad humana. Es una trampa que resulta incluso más intensa para los hombres que para las mujeres, pues para estas el sentido de la igualdad, entendida como igualación con los hombres, constituía una aspiración; en el caso de los hombres, la igualación la percibe como un descenso. Pero esta dicotomía es falsa y sólo aparece así ante quien sigue conservando una mirada patriarcal de las relaciones.

La visión femenina que tenemos disponible los hombres y que todavía no nos hemos atrevido a explorar nos impide apreciar las virtudes de dichas experiencias. El patriarcado se ha afanado por darle sentido a la vida entendida como una competencia en el ámbito social, dejando el espacio privado como una esfera destinada al dominio discrecional de cada padre de familia. Seguramente, la mayoría de las mujeres están encantadas de su oportunidad biológica de la maternidad, pero rechazan el intento patriarcal de perpetuar su esencia a una maternidad normativa, en la que han de ser madres según el diseño de una cultura que ha establecido dicha opción como exclusión de otras posibilidades vitales. La igualdad de género hay que pensarla desde esta 
doble vía de recuperación de los valores y los espacios femeninos por parte de los hombres y de los valores y espacios masculinos por parte de las mujeres. No para producir una inversión, sino para lograr un desarrollo que integre ambos elementos en nuevas síntesis de identidad que nos haga a todos más humanos. El modo de operar un cambio en la construcción de la identidad ha de comenzar por educar desde la infancia y el primer referente educativo es el ejemplo. Nada se aprende mejor que queriendo ser como aquellas personas a quienes uno admira. Si ser como papá excluye ser como mamá, se comienza a generar una dicotomía simbólica que niños y niñas asumen de modo espontáneo como referentes de su identidad.

Quizás una manera de equilibrar esta descompensación sea asumiendo su función maternal, atendiendo al cambio progresivo de la vida con su multitud de facetas. Saber vivir como un arte de encontrar equilibrio en el conjunto de esferas públicas y privadas, sabiendo conceder a cada situación su justo valor. Precisamente aquí radica con frecuencia la diferencia entre el modelo psicológico femenino y masculino. Las mujeres presentan un pensamiento más circular porque todos los acontecimientos están interrelacionados, se mueven con una lógica de la dependencia y sus decisiones deben estar graduadas y acorde con sus responsabilidades hacia los demás. La educación requiere una dedicación a atender el cuidado de los hijos y esto también es un trabajo, un enorme trabajo, que debe ser apreciado como parte de la contribución a la sociedad. Por eso, someter la maternidad a presiones que supongan la exclusión de la vida profesional o familiar supone una estrategia equivocada. La política hacia la maternidad debe ser de conciliación y no como un derecho que se les concede a las mujeres, sino como un proyecto de una sociedad que entiende su desarrollo integrando generaciones y estableciendo condiciones no sólo materiales sino también afectivas como parte del bienestar social.

La miopía social puede propiciar que este objetivo sea percibido como una reivindicación de las mujeres, pues es la parte perjudicada la que clame frente a la injusticia. Pero desde una perspectiva más amplia, se trata de un objetivo al que debe aspirar la sociedad como un bien común para todos. La educación de los hijos no puede verse comprometida por un modelo de "laborismo" patriarcal que identifica exclusivamente el éxito social con la dedicación al trabajo. El abandono del espacio privado, presentado como un signo de liberación en la publicidad, por ejemplo, constituye también un abandono de "la maternidad", en un sentido más amplio y a la que están llamados tanto el hombre como la mujer. La vida no hace "media", como cuando hacíamos los parciales de una asignatura. Los diferentes ámbitos de nuestro desarrollo personal que no realizamos no pueden ser compensados con los éxitos de otros. Algunos de esos ámbitos son esenciales para la propia identidad personal. Por ejemplo, la condición de padre requiere una dimensión afectiva y comunicativa que no puede reivindicarse en virtud del título que concede el libro de familia. Los papeles no son la vida. Esta existe en la espontaneidad de las relaciones y en los valores que se construyen en cada espacio humano. En este sentido, la educación de las mujeres, sin esconder las muchas injusticias que ha llevado aparejada, hay que contemplarla como un nicho ecológico de los valores humanos. Ellas han sabido atender sus responsabilidades sabedoras de su condición dependiente, con proyectos profesionales adaptados a otros ámbitos de su responsabilidad. El proyecto de igualdad no debe servir sólo para producir más personas masculinizadas, basada en mentalidades que contemplan el éxito en la independencia, la competencia para alcanzar objetivos personales. Existe otra medida que corresponde a lo que tradicionalmente se ha asociado con lo femenino, pero que pertenece por igual a los hombres La maternidad no consiste exclusivamente en albergar una criatura dentro del propio cuerpo, lo cual es privilegio consignado a las mujeres, sino en alojar la existencia de esa persona que es tu hijo o hija dentro del mundo. A esta tarea están llamados por igual el padre y la madre, pues son dos referencias constitutivas de la identidad humana. La renuncia a la maternidad del padre propiciará, en buena medida, la discriminatoria a través de la cual sus hijos e hijas verán el mundo. No ha de extrañar entonces que los hijos varones entiendan como parte de su identidad masculina el abandono del espacio privado.

La maternidad masculina ha de ser una de los pilares sobre los que se construya un nuevo concepto de identidad del hombre para entender que las posiciones que se ocupan en el espacio público y privado son reversibles entre hombres y mujeres y no corresponde de manera sustancial a ningún cuerpo. La feminidad como conjunto de valores asociados tradicionalmente a las mujeres, tales como el cuidado y el afecto filial que lo acompaña, nos corresponde también a los hombres. Hasta que no se consiga evidenciarlo como una pérdida de sus oportunidades vitales, posiblemente asistiremos a un modelo desequilibrado en la igualdad entre hombres y mujeres, entendido este concepto de la igualdad como una espuria aspiración por alcanzar un modelo de éxito androcéntrico construido sobre el lenguaje de los derechos del liberalismo.

Reforzar la imagen de la mujer como exclusivamente "madre" ha sido una de las estrategias del patriarcado para mantener la escisión entre el espacio privado y el espacio público, lugar caracterizado por ser el escenario de "fuerzas" en el que se desarrolla la actividad con otros iguales, al menos, en la condición identitaria de hombres. Por eso, el poder ha sido tradicionalmente de los hombres, mientras que las mujeres han quedado como sujetos poseídos, pertenecientes a un "señor". De ahi procede la distinción que todavía podemos encontrar como un residuo del patriarcado entre "señorita", que sería la hija de un señor, y señora, como mujer del señor, cuyo estatus y poder social deriva de su marido. Por eso todavía escuchamos la expresión 
de "señora de", y la prueba más clara de este orden de ascendencia social se encuentra en la adopción del apellido del marido en la cultura anglosajona.

\section{Patriarcado y educación de género}

La presunción cultural e incuestionable es que lo masculino es superior a lo femenino y se establece una escala jerárquica por la que desarrollar cualidades supuestamente masculinas se estima como una aspiración, mientras que las funciones y actitudes femeninas se ponderan como de menor valor. "Ser o comportarse como un hombre" tiene una serie de connotaciones que sugiere ya ciertas actitudes predominantes. En cambio, "ser o comportarse como una mujer", adquiere connotaciones que pretenden aludir a cierta falta de carácter o personalidad a la hora de llevar a efecto determinadas decisiones. Se polariza ambas categorías bajo una falsa dicotomía de la racionalidad fría y resoluta que caracteriza a los hombres frente al carácter sensible y supuestamente indeciso de la mujer.

Por tanto, lo masculino y lo femenino se ha planteado como una escala de valor psicológico y moral de la personalidad. Para las chicas asumir roles masculinos es una manera de igualarse, y lo expresan como proyecto positivo, pero no se puede decir lo mismo en la dirección de los chicos con respecto a las chicas, que sería una manera de perder valor frente a los hombres (sus iguales, que participan del mismo poder social).

Esta situación ha creado un falso espejismo en relación a la igualdad, pues esta transita en una sola dirección y, lamentablemente, no es la mejor. Básicamente se está perdiendo una parte de los valores que correspondía a nuestra condición humana y que venía hasta ahora preservado por la cultura de las mujeres, aunque esto fuera realizado a costa de un enorme sacrificio personal. Se está imponiendo el discurso del colectivo prevalente en el análisis de la igualdad entre hombres y mujeres. Se mide la igualdad por los derechos, lo cual ha permitido hasta cierto punto descubrir las incoherencias de un proyecto emancipador diseñado exclusivamente por hombres y para hombres, bajo el formato de "los derechos sujetivos" para la igualdad política de los ciudadanos.

Sin embargo, este criterio de "los derechos" generado en el seno de la cultura androcéntrica ha agotado su capacidad explicativa para seguir avanzado en un proyecto de igualdad real. A nuestro juicio, se ha producido una desertización de la realidad humana que entraña el cuidado mutuo como una responsabilidad personal y cívica por un concepto de raíces legalistas que intenta pesar y medir la libertad humana en cada ámbito. Así las cosas, la libertad de uno se extiende hasta donde toca con la libertad del otro, en cambio, en el modelo del cuidado mutuo las libertades no se confrontan sino se unen y aumentan, bajo un sentido de la relación diferente. Se trata de dos paradigmas filosóficos: la ética de los derechos y la ética de la responsabilidad, los cuales no son ajenos uno del otro. Lo cierto es que hasta ahora nuestra cultura ha estado subsumida y educada en la cultura de los derechos, a los cuales hay que reconocerles enormes beneficios para clarificar la prevalencia de la libertad individual frente a adherencias comunitarias injustificadas, pero también es un instrumento conceptual que tiene sus limitaciones. La principal, a nuestro juicio, radica en la imposibilidad de remitirse al origen en el que se produce la desigualdad y, por tanto, sus soluciones se asemejan a señales de tráficos de vehículos que vienen de fábricas construidos de muy distintas formas. El problema no está en cómo se regula la convivencia, sino en cómo se construyen los sujetos que la comparten. Por supuesto, el Derecho tiene una importante función normativa y también pedagógica para enseñar a los sujetos el valor de ciertos comportamientos. El hecho mismo de que algo pueda ser sancionado por la ley constituye, prima facie, una marca moral sobre el valor de la conducta. Sin embargo, esta es la punta del iceberg que ha de ser removido desde la base.

Sin duda, los derechos han contribuido de manera fundamental a mejorar las condiciones de las mujeres. Incluso podríamos decir que han sido decisivos para visibilizar ciertas discriminaciones entre hombres y mujeres. Cuestiones tan obvias como la capacidad de ser sujeto activo en la elección de los representantes públicos, el derecho a los sistemas de educación u otras reivindicaciones básicas para igualar la posición de la mujer con la de los hombres. Por tanto, hemos de estar atentos a no tirar al niño con la bañera. Los derechos han sido y siguen siendo útiles y necesarios, pero insuficientes. Se necesita implantar otra lógica basada en un concepto de responsabilidad compartida que impregne todos los ámbitos de la relación, desde lo privado a lo público. Se trata de un concepto con más potencialidad educativa y ética que jurídica. La responsabilidad compartida rompe la lógica de una convivencia de sujetos autónomos y reivindica valores comunes que forman parte del bienestar de cada cual. La lógica de la pertenencia no puede ser meramente formal, requiere participar en tareas que no son retributivas en términos económicos pero que reportan un beneficio humano en términos de convivencia. La lógica del mercado no puede seguir siendo el referente del éxito. La identidad del hombre no se define por su capacidad de depredador social para abastecer a su familia, ni la de la mujer basada en el sacrificio como forma de afirmación. La responsabilidad exige entender la vida desde los propósitos y no desde de los derechos. La responsabilidad familiar, por ejemplo, no puede ser repartida a cuadro como si fuera un tablero de ajedrez, existe algo intrínseco que define la familiaridad y tiene que ver con una disposición común a tener cuidado unos de otros. Por tanto, la lógica de los derechos ha de ser expansiva en su interpretación para atender situaciones que deben ser redefinidas por los valores compartidos. 
Esta tarea no corresponde a las normas jurídicas, aunque estas pueden contribuir a posibilitar los cambios favoreciendo ciertas inversiones educativas que ilustran el valor positivo de una conducta. Por ejemplo, el permiso de paternidad ha de contribuir a la distribución del trabajo doméstico y la tarea común de crianza de los hijos. Se trata no sólo de un derecho de la mujer a compatibilizar su vida personal y profesional, sino también de educar en un derecho de los hombres a participar en la experiencia de la maternidad. No se trata exclusivamente de la ayuda material sino también y principalmente de educar en igualdad. Ahora bien, la clave no está en que las mujeres entiendan exclusivamente esta posibilidad como un derecho frente a los hombres, sino que los hombres la conciban como un derecho y una responsabilidad de hacer más efectivo el sentido de pertenencia a la experiencia de la maternidad. Si no fuese así, podría desvirtuarse el sentido de la norma y entender algunos que esta posibilidad es una especie de vacaciones por ser padre, un premio por incrementar el índice de la natalidad. Por tanto, la primera tarea para alcanzar una igualdad definida de manera plural ha de consistir en romper criterios normativos ("patrones", el propio término nos indica cuál es el referente de medida) construidos sobre modelos de identidad que presuponen una jerarquía de valor asociado a lo masculino y a lo femenino. A nuestro juicio, la igualdad ha de encaminarse hacia una recuperación de los valores asociados a lo femenino. La óptica educativa que desarrollada por las mujeres ponderaba el tiempo, el espacio y la relación de un modo distinto a los hombres. Concedían un valor intrínseco al encuentro con el otro, al cuidado que se le dispensaba y lograban de manera invisible hacer que las personas nos sintiéramos con valor. Esta tarea que muchos recordamos como una virtud callada de nuestra madre, apuntaba un valor que hoy día está desapareciendo. No se trata de elogiar la abnegación personal que, por otro lado, para nada ellas lo vivían así, sino reivindicar formas de vida que tienen que ver con valores humanos que concedían a cada gesto y a cada ocasión un valor entrañable. Frente a este modelo, los hogares se han convertido en aparcamientos humanos, de sujetos que llegan a casa para descansar de los kilómetros de vida. La privacidad que antes era una vida llena se ha vaciado, es decir, se ha convertido en espacio realmente privado, pues incluso las preferencias domésticas vienen impuestas por modas públicas. Se rompe también el concepto espacio temporal y no se comparte con el otro la presencia, la cual se convierte con frecuencia en una ausencia dibujada en el espacio, y se persiste por desarrollar una comunicación fuera del lugar. El mundo virtual produce la seducción de ser entendido donde no existe realidad. Cada vez hay más medios de comunicación y con ellos más incomunicación privada. Hemos de avanzar en el sentimiento moral de las mujeres, pero los sentimientos no surgen fuera de la realidad que los engendran. Por eso, creemos que educar en los valores femeninos, la interacción horizontal, desarrollar una mirada compleja a los conflictos relacionales, con soluciones abiertas a la situación vital de cada cual, sin establecer formulas universales, harían la convivencia más humana. No se trata de una mera actitud ética, sino de un principio que revolucionaría también el espacio público, aportándole el carácter horizontal y dinámico de una vida que tiene que ser construida sin escisiones de lo público y lo privado. El éxito en el espacio público a costa de un sacrificio de la vida privada sería una victoria pírrica. Estaríamos consolidando un mundo mejor con personas más infelices, enriqueciendo con vida cada vez más pobre y lamentando carecer de eso que se ha dado en llamar "calidad de vida", un buen eufemismo para referirse a los valores defendidos hasta ahora por las mujeres. Esa es la desgracia, que los hombres parece que no tienen que aprender nada de las mujeres y cuando lo hacen, le denominan de otra forma: calidad de vida, como un éxito de la cultura del trabajo, que permite también como premio estar tiempo con la familia.

Por otro lado, he escuchado a algunos hombres referirse a la angustia de ser hombre en una sociedad desigualitaria cuando pretende desarrollar una convivencia más familiar con sus hijos. En primer lugar, el sentimiento a que pueda ser cuestionada su valía profesional por no dedicarse a ella de pleno. También aquí funciona el tiempo de asociar la cantidad con la calidad. Se trata de aguantar en el puesto de trabajo, de rendir en ocasiones esfuerzos tribales que forman parte del imaginario del poder en los centros de trabajo. En segundo lugar, como se le presupone la valía, la de ser hombre, su acercamiento al ámbito de lo femenino puede traer consigo un cuestionamiento social de aquello que se le presume. Otros, de manera más cínica, argumentan que no se debe cometer la temeridad de colaborar en las tareas domésticas, pues si te salen bien corres el riesgo de que te animen a repetir. Ser "un manaza" tiene más beneficios, por lo que ejercer de hombre es una buena manera de seguir señalándole a las mujeres sus tareas propias, en cambio, sí puede ser un "manita", no por el tamaño de la manos, sino porque a él queda encargado el trabajo fino, aquel que consiste en reparar los artilugios tecnológicos o colocar la bombilla. Se produce una vez más la separación entre inteligencia y el "trabajo doméstico" en términos de "especialización" no tecnológica sino de género. Por eso la mamá limpia la cocina, trabajo interior y, el papá, si limpia, limpia el coche, objeto por excelencia de la nueva caballería urbana.

El hecho de presuponerle "valor" (público) por ser hombre, le sitúa ante un sentimiento ambiguo ante sus opciones de compartir su tiempo y sus intereses con la vida familiar. Cuando lo hace se convierte en objeto de película cómica o de anuncios que quieren ilustrar más las virtudes del producto que del padre: comidas que se preparan de manera mágica, asumiendo así el mismo rol que la madre pero dejando claro su figura de padre. Un ejemplo de este nuevo modelo de igualdad producida gracias a la magia de la publicidad, lo encontramos en el spot de Gallina Blanca, en el que aparece el padre "cocinando", mientras el niño le graba con intenciones de mostrárselo a su madre y decirle que "quiero que cocine él". El mensaje que pretende 
transmitir está claro: la comida que prepara la publicidad está mejor que la preparada en casa y le gusta más a los niños, la prueba fehaciente es que el niño prefiere que lo haga quien no se encarga habitualmente de hacerlo. La magia está en el producto. Cuando el padre advierte que el niño le está grabando le ordena apagar la cámara, no vaya a ocurrir que la madre lo descubra y le sugiera encargarse de esa tarea.

Las tareas del hombre en el hogar son consideradas una "ayuda", un gesto de voluntariedad solidario, una ONG doméstica, y no como un trabajo que se ha de compartir por igual. En cambio, el padre sí aparece en el espacio doméstico en ratos de esparcimiento nocturno, tras finalizar el día, como elemento de seguridad, y acompaña a sus hijos en aquellas actividades que requieren la instrucción y el ingenio tecnológico de papá: ayuda a construir coches y barcos o artefactos tecnológicos que le permite compartir con sus hijos ratos de diversión "inteligentes".

Un papá dando la merienda, preocupado por la comida o pendiente de idas y llegadas de sus hijos no constituye un papá feliz en el modelo publicitario. Mejor dicho sólo lo podría ser si, además, lo combina con su éxito profesional. Para eso se utiliza el símil del maletín, la corbata o gestos masculinos que signifiquen la seguridad de su éxito social. Sigue existiendo una resistencia cultural a representar la "personalidad del padre" con los valores tradicionalmente asociados a "la madre", no por invertir y cambiar la posición entre ellos, sino porque ambos pueden aspirar a realizar un modo de vida en la que dichas funciones no vengan determinada socialmente por una marca sexual, convertida en categoría sociológica (género).

La igualdad debe ser un término abierto a los valores expuestos a un lado y otro de nuestra identidad humana: lo masculino y lo femenino. Somos personas, ambos elencos de cualidades forman parte de nuestro desarrollo potencial. $Y$ aquello que no somos nos pertenece como una voz callada, como una disposición permanente que se ha de activar en cualquier oportunidad que nos ofrezcan las relaciones familiares, sin establecer funciones categóricas que cercenen nuestro desarrollo personal. Incluso cualidades supuestamente ligadas de manera tan radical a lo biológico como la maternidad, están abiertas del modo más completo al padre. Pues una madre tiene a su hijo nueve meses en su vientre, pero después está mucho más tiempo fuera y el desarrollo afectivo puede ser compartido en el mismo nivel y grado. Lo biológico no debe condicionar nuestra naturaleza más intensa, aquella que surge de nuestra creatividad como persona en un entorno de relaciones familiares. Y en el ámbito de la moral, la práctica forma parte de la esencia del bien, por lo que solo practicando aquello que queramos ser podremos conseguirlo.

INVENTANDO LAS DESIGUALDADES
Esta diferencia está también basada en otro presupuesto de nuestra cultura: la desigualdad de los seres humanos, marcada por su particular actividad manual o intelectual. El trabajo manual se estima de menor valor frente al intelectual. Si fuese así, se debería de facilitar que todos puedan desarrollar ambas actividades o especialmente la vida intelectual. Con posterioridad se llega a justificar lo que en muchas ocasiones fue una cuestión de oportunidades vitales como un mérito personal. La injusticia convierte su realidad en su propio argumento de defensa.

Esta diferencia que debería ser como un recurso común para alcanzar una vida mejor para todos, ha sido utilizada como un instrumento de desigualdad. La inteligencia ha establecido una especie de "nobleza" frente a la servidumbre de quienes se han visto abocados a una labor manual. Esta concepción ha favorecido que el éxito sea relacionado con aquellas actividades que no exigen un esfuerzo físico. La asistencia y el cuidado, tareas que no persiguen más objetivo que la atención al bienestar de quien lo precisa, no es una tarea intelectual ni atractiva. Las tareas, labores y otros términos que denotan una rutina mecánica de vida parecen aisladas de la supuesta vida activa del intelecto. Ambas tareas son complementarias y necesarias. Pensar es básico para la acción, pero la acción es la que ofrece las claves para el pensamiento.

Si a este dato unimos que los hombres por naturaleza eran considerados como el elemento activo e intelectual de la relación familiar, frente a la función auxiliar de cumplir con las tareas domésticas de las mujeres, tenemos los ingredientes necesarios para que la inversión de dichas funciones sea apreciada como un fracaso por los hombres a los que les toque asumir funciones asociadas al imaginario femenino $\mathrm{y}$, por tanto, consideradas inferiores. Se produce así una justificación tácita del absentismo laboral por parte del hombre en el hogar basado en estos dos prejuicios culturales que pretenden hacer de una diferencia inventada un motivo de desigualdad.

La presunción de "superioridad" de la inteligencia resulta más injusta cuando se pretende alegar como mérito personal posiciones sociales que han sido conseguidas por el esfuerzo invisible de muchas otras personas que realizaron tareas auxiliares para tal empresa. El mérito individual se vuelve muy cuestionable cuando prescindimos de las condiciones necesarias para alcanzarlo. Suelen ser las oportunidades vitales más que la inteligencia las que definen posiciones en la sociedad. Por supuesto, hay que conceder toda la importancia que tiene una vida intelectual activa y crítica, pero resulta empobrecedor separarla de la parte material de la vida humana.

Existe una parte de la vida que tiene que ver con el ámbito de las relaciones, de los compromisos, de los afectos. La inteligencia siente y consiente, es capaz de participar en la vida de los demás y hacerlo desde la posición de igualdad intrínseca de ser para el otro quien eres, sin más. Solo la igualdad permite disfrutar de dicha situación, por eso, la inteligencia invita a participar de la vida de los otros también en esa dimensión 
que requiere la colaboración física, las tareas por las que se demuestra sentir y ser igual a cualquier otro. La inteligencia humana no lleva a separarnos de los demás sino a acercarnos, pues conocemos a través de los sentimientos. Sólo cuando llegas a sentir cómo es el otro, uno sabe cómo actuar. Por eso, la inteligencia exige un descenso a la cotidianidad con el otro como modo auténtico de conocimiento.

\section{EDUCAR EN IGUALDAD}

La igualdad tiene que ser entendida en un sentido moral, compatible con el hecho incuestionable de la diferencia. Pero ser diferentes no significa practicar desigualdades arbitrarias. La diferencia es una condición para la igualdad, pues sólo aceptando el encaje de funciones como una convención dinámica, abierta y como parte de un bien conjunto, es posible ejercer la igualdad en valor. Se trata de entender entonces que lo que se hace, además del ejercicio de un derecho, constituye un bien más intenso referido al valor que se comparte con el otro como persona. Esta consideración de la igualdad como valor de la dignidad del otro ha de estar en la base de la relación de géneros.

No se trata de una mera actitud de respeto como indiferencia a la suerte del otro, una especie de igualdad basada en la indiferencia, sino de una tarea que implica favorecer los proyectos del otro como parte de una relación que se alimenta de los progresos que cada uno pueda obtener. Estos progresos no se refieren sólo a los éxitos profesionales o de la vida pública, sino también al bienestar que incluye las expresiones de la vida privada. En este sentido, la igualdad entre hombres y mujeres, es decir, entre cualquier miembro que forme parte de la convivencia, es una condición indispensable de cualquier otra forma de bienestar. Muchas de las tensiones latentes en la convivencia radican en la falta de respeto a esta forma de igualdad ética, a dirimir diferencias con base en un concepto individualista de "derecho" que falsea su sentido dentro del ámbito de la convivencia familiar (por ejemplo, quienes consideran que su posición económica le permite ciertos privilegios con respecto al otro porque él trabaja y el otro no) Creo que esta es la base sobre la que hay que construir una ética de la igualdad. Si no existe este sustrato, cualquier discurso será papel mojado. La igualdad no se declara, se construye y para ello es necesario avanzar en un sentido de respeto a la dignidad del otro.

El principal problema de la violencia de género radica en modelos educativos de una cultura patriarcal que desarrolla sentimientos vinculados a la identidad de género tremendamente discriminatorios. Así, el fracaso o el éxito de cada género viene medido por parámetros de un modelo androcéntrico caduco. Los valores y funciones asociadas a los géneros están llamados a ser más abiertos en un mercado de trabajo dinámico y precario, el cual está obligando a romper estereotipos individuales y concebir la convivencia desde la perspectiva común de la pareja o la familia. Sin embargo, la mentalidad no ha evolucionado con la celeridad de los acontecimientos y estos cambios han cogido desprevenidos a muchos hombres, que aferrados a una educación patriarcal se resisten a aceptar la inversión de roles. La igualdad debe ser ante todo un asunto de respeto a la dignidad, por tanto, nadie es más ni menos por desempeñar la tarea que realiza. Nuestra cultura está basada en una idea del mérito que convierte las ventajas particulares en motivos para la diferencia y, con frecuencia, para la discriminación, aunque esta venga envuelta en una apariencia aterciopelada. Así, por ejemplo, desde los griegos, se resalta el intelecto como una cualidad específica de lo humano y las actividades relacionadas con su ejercicio son ponderadas de mayor valor, frente a las tareas manuales. Esta diferencia, que en teoría debería ser entendida como una cualidad que exige mayor responsabilidad por parte de quienes la ostentan, se esgrime como una especie de nobleza humana que permite distinguir entre el metal de las personas.

Este argumento aparentemente superado sigue presente en nuestra sociedad. La igualdad en muchas ocasiones se ha entendido como una aspiración a pertenecer a otra clase social, a la de las personas que desempeñan un trabajo no manual y que sea retribuido. Esta actitud no es injustificada, si tenemos en cuenta que nuestra cultura ha basado el valor de las personas en su proyección pública, quedando el ámbito privado como el ámbito olvidado. Quien allí permanece no existe y, además, existe menos en una sociedad individualista en la que se pueda establecer una diferencia definitiva entre miembros de la comunidad familiar que aporten distintas capacidades y distintos ingresos. A las mujeres se les educa con el sentimiento de ser responsable de atender tanto los cuidados familiares como su vida profesional y cuando llegan estos se presentan como un dilema excluyente, parece que su trabajo vale menos por centrarse en los asuntos familiares. ¿Hará falta que todas las madres se pongan en huelga para que la sociedad tome conciencia del servicio público que se ejerce en la vida privada? ¿Ha sido necesario que nuestros mayores hayan llegado a estar desatendidos para reconocer que la atención a personas dependientes es un trabajo que tiene una dimensión pública? ¿Debe la Administración pública encargarse de nuestros hijos desde que nacen para garantizar una completa igualdad en las aspiraciones profesionales de hombres y mujeres? ¿Y cuidar también de nuestros padres? ¿Y cuidar de nosotros cuando caigamos enfermos? ¿Qué modelo de sociedad estamos creando con una incesante tarea de promoción y de alcanzar mayores recursos a costa de abandonar bienes que tienen un valor humano insustituible? Pues ha sido precisamente la acción de las mujeres en la política la que ha sensibilizado a los legisladores sobre la importancia de que el cuidado también es asunto público. ¿Pero cuánto le costaría al Estado asumir este tipo de servicio? Y aun cuando pudiera hacerlo, ¿no se estaría perdiendo algo esencial del valor familiar y comunitario de las personas? 
El discurso de la igualdad de género guiado por la perspectiva androcéntrica ha contribuido a acentuar la desigualdad en términos de individuos asalariados e individuos dependientes, sin ponderar suficientemente la igualdad como proyecto común en la convivencia. Este resultado es lógico, si tenemos en cuenta que el modelo de "derechos" liberal estaba asociado a la condición de propietario. Quien no tiene recurso no tiene derechos. Por tanto, la libertad significa conseguir una posición económica independiente para hacer valer tu condición de sujeto con derechos efectivos. En cualquier otro caso son meros derechos "presuntos". Esta es la situación de fisura abierta y de mayor calado entre quienes asumen la igualdad como una mera forma de tener lo que sólo los hombres han tenido hasta ahora. Y no está mal esta aspiración. Todo lo contrario, había que desbaratar el hechizo androcéntrico de que tener derecho era tener "poder" tal y como era concebido por ellos de tener una posición y recursos para reclamar independencia. Pero una vez conseguido esto, qué significa la igualdad. ¿Cómo queda la otra parte de la vida de las personas que no consiste precisamente en esta dimensión pública y profesional? Pues reducir toda la vida sólo a ello sería demasiado pobre, no disponer de un ámbito afectivo de amigos o familia que permita gozar de diversión e intimidad. Existe un importante riesgo de vacuidad.

\section{LA RESPONSABILIDAD DE LOS MEDIOS DE COMUNICACIÓN}

A ser iguales se aprende jugando, pues en esas formas aparentemente desenfadadas y lúdicas del juego se representan los primeros escenarios simbólicos de nuestra identidad. Niños y niñas ensayan a ser alguien: "papá", "mamá", "la médica" o quien sea. Pero hay un elemento de representación espontáneo en su entorno con el que se identifican y lo imitan porque existe una atracción lúdica de la praxis de los adultos. Dado el importante poder que los medios de comunicación tienen en la emisión de modelos de representación social, constituyen una referencia básica para la formación de los pequeños. A través de los cuentos infantiles los niños se proyectan en sus personajes, quieren ser como esos dulces personajes de multicolor que les transmiten emociones y lo asocian a un determinado modo de ser cuya única justificación es la de su identidad sexual. Así, por ejemplo, resulta muy natural cuando pensamos en un personaje negativo de mujer que se nos venga a la cabeza una bruja y en el personaje positivo del hombre que sea un sabio. Resulta difícil la inversión de personajes brujos y mujeres sabias, pues el poder del conocimiento en las mujeres siempre parece estar contaminado de malas intenciones, como si fuese una herencia de la desobediencia edénica. Los personajes si son buenos, tienen que ser también bellos, y la belleza se vende como condición de éxito social y señal de bondad. Frente a la bruja tenemos a la princesa, la cual culminará su éxito con un príncipe azul. La historia de la identidad femenina pasa siempre por ser la mujer de alguien, cuya suerte radica en que sea la del poderoso que, además, es guapísimo.
También a través de los juegos los niños interpretan el mundo que les circunda. Con la misma naturalidad que adquirimos una ubicación física logramos también una ubicación psicológica y social, que nos viene dada a través de los diferentes esquemas de interacción. El juego es un código de conducta social que los pequeños aprenderán casi sin darse cuenta. En muchos casos la identidad de género está muy marcada y se concibe como una preparación sobre las aspiraciones que el pequeño o la pequeña debe desarrollar en la edad adulta. Así los propios familiares se encargan de recriminar a los pequeños opciones lúdicas que estimen desviadas respecto a las cualidades que deben acompañar a su crecimiento psicológico y social. "Esto es de niño" o "esto es de niña" se escucha con demasiada frecuencia y se le impone a los niños como códigos invisibles sobre cuáles deben ser sus características psicológicas. Así, por ejemplo, las niñas son educadas en tareas más participadas y de asistencia, a través del juego con muñecos, mientras a los niños se les invita más a los juegos de acción y que entrañan una competencia, la cual permitirá diferenciar un orden jerárquico en el éxito logrado.

En resumen, se imponen mandatos de géneros que los niños o niñas interiorizan sobre lo que "debo hacer" o "no debo hacer", justificada en la idea de un "yo soy", referido a su identidad de género, categórico. Será el techo identitario que condicionará sus posibilidades como persona. Los medios son educadores permanentes de la ciudadanía y la igualdad de género ha de estar presente tanto en los contenidos como en las formas, evitando que la mujer siga siendo representada como un sujeto auxiliar del hombre dedicado al cuidado de la familia, mientras el hombre se representa como el hombre público e independiente en el que su vida con mayúscula es una vida ajena al entorno de los sentimientos y dependencias familiares.

\section{REFERENCIAS BIBLIOGRÁFICAS}

Amorós, C., “Ética y Femeninismo", en GUARIGLIA, O. ed., Cuestiones morales, Trotta. Madrid, 1996.

----, Tiempos de Feminismo. Sobre el feminismo, proyecto ilustrado y postmodernidad, Cátedra, Madrid.

----, “Feminismo e ilustración”. (XIV Conferencia Aranguren, 2005), Isegoría, 34, 1997, Madrid, pp. 129-166.

Bach, M. y otras, El sexo de las noticias: reflexiones sobre el sexo en la información y recomendaciones de estilo, Icaria, Barcelona, 2000.

Beltrán, E., Maqueira, V., Álvarez, S. Y Sanches, C., Feminismos. Debates teóricos contemporáneos, Alianza Editorial. Madrid, 2001.

Benhabib, S., "El otro generalizado y el otro concreto: la controversia Kohlberg-Gilligan y la teoría feminista", en Seyla Benhabib y Drucilla Cornell, eds. Teoría feminista y teoría 
crítica. Ensayos sobre la política de género en las sociedades del capitalismo tardío, 1990, Alfons Magnànim, pp. 119-151.

----, Situating the self. Gender, community and postmodernism in contemporary ethics, Cambridge. Polity Press, 1992.

Benhabib, S. y Cornella, D. ed. (1990), Teoría feminista y teoría crítica, Editorial Alfons el Magnanim, Generalitat Valenciana, Valencia, 1990.

Bordieu, P., La dominación masculina, Anagrama, Barcelona, 2000.

Castell, C., Perspectiva feminista en Teoría Política, Paidos, Barcelona, 1996.

Chodorow, N., “Gender as a Personal and Cultural Construction”, Signs, 20, 1995, pp. 516-544.

Cobo, R., Fundamentos del patriarcado moderno. J.J. Rousseau, Cátedra, Madrid, 1995.

Figes, E., Actitudes patriarcales: las mujeres en la sociedad, Alianza, Madrid, 1980.

Gilligan, C., In a Different Voice, Harvard University Press, Cambridge, 1982.

Gilligan, C., Ward, V., Mapping the Moral Domain, Harvard University Press, Cambridge, 1988.

González, A. y Lomas, C., Mujer y educación, Editorial Grau, Barcelona, 2002.

Goodwin, R. y Pettih, ed., Ph., Contemporany Political Philosophy, Cambridge, Blackwell, 1997.

Held, V., “The Meshing of Care and Justice”, Hypatia, 10, 1995, pp. 128-132.

----, “Care and Justice in the Global Context", Ratio Juris, 12, 2004, pp. 141-155.

Kohlberg, L., "The Claim to Moral Adequacy of a High-test Stage of Moral Judgment", The Journal of Philosophy, 18, 1973, pp. 630-646.

Lomas, C., "El aprendizaje de las identidades femenina y masculina en la cultura de masas", en González, A. y Lomas, C., Mujer y educación, Editorial Grau, Barcelona, 2002.

----, ¿Iguales o diferentes?: género, diferencia sexual, lenguaje y educación. Paidós, Barcelona, 1999.

López De la Vieja, M. T., “Feminismo como crítica”, en José Rubio Cariacedo, José María Rosales y Manuel

Toscazo, Retos pendiente en Ética y Política, Trotta, 2002.

----, “Ética y género”, en José M. García Gómez-Heras, coord. Dignidad de la vida y manipulación genética. Bioética, ingeniería genética, ética feminista, deontología médica, Biblioteca Nueva, Madrid, 2002.

López De la Vieja, M.T., La mitad del mundo. Ética y critica feminista, Ediciones Universidad de Salamanca, Salamanca, 2004.

Mackinnon, C.A., Hacia una teoría feminista del Estado, Cátedra, Madrid, 1995.

Mill, J.S. y Taylor Mill, H., Ensayos sobre la igualdad sexual, Cátedra, Madrid, 2001.

Miyares, A., Democracia feminista, Cátedra, Madrid, 2003.

Nash, M., Mujeres en el mundo. Historia, retos y movimientos, Madrid, Alianza Editorial, 2004.
Okin, S., Women in Western Political Thought. Princeton University Press. Princeton, 1978.

----, "Desigualdad de género y diferencias culturales", en Castell, C., Perspectiva feminista en Teoría Política, Paidós, Barcelona, 1996.

Osborne, R., La construcción sexual de la realidad, Cátedra, Madrid, 1989.

Pateman, C. “Críticas Feministas a la dicotomía Público/ Privado”, en Castell, C., Perspectiva feminista en Teoría Política. Paidós. Barcelona, 1996, pp. 31-52.

Puleo, A. H., Condorcet, De Gouges, De Lambert y otros. La Ilustración olvidada. La polémica de los sexos en el siglo XVIII, Anthropos, Madrid, 1993.

Rivera Garreta, Mํㅗ. Nombrar el mundo en femenino. Pensamiento de las mujeres y teoría feminista. Icaria. Barcelona, 1994.

Shlain, L., El alfabeto contra la diosa: el conflicto entre la palabra y la imagen; el poder masculino y el poder femenino, Debate, Madrid, 2000.

Suárez Villegas, J.C., La mujer construida. Comunicación e identidad femenina, Trillas Eduforma. Sevilla, 2006.Valcárcel, A., El miedo a la igualdad, Crítica, Barcelona, 1993.

----, Sexo y Filosofía: sobre mujer y poder, Anthropos, Barcelona, 1994.

----, La política de las mujeres, Cátedra, Madrid, 2004.

Wollstonecraft, M. (1791(1996), Vindicación de los derechos de la mujer, Cátedra, Madrid.

Young, I.M., "Imparcialidad y lo Cívico Público", Algunas implicaciones de las críticas feministas a la teoría moral y política” en Benhabib, S. y Cornella, D. ed., Teoría feminista y teoría crítica, Editorial Alfons el Magnanim, Generalitat Valenciana, Valencia, 1990. 